\title{
Identification of Echinococcus granulosus strains using polymerase chain reaction-restriction fragment length polymorphism amongst livestock in Moroto district, Uganda
}

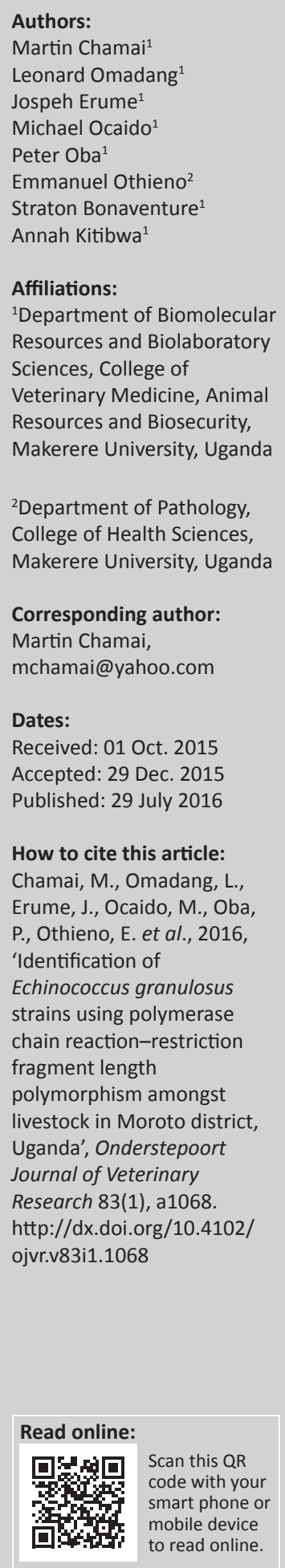

A descriptive study was conducted to identify the different strains of Echinococcus granulosus occurring in livestock in Moroto district, Uganda. Echinococcus cysts from 104 domestic animals, including cattle, sheep, goats and camels, were taken and examined by microscopy, polymerase chain reaction with restriction fragment length polymorphism and Sanger DNA sequencing. Echinococcus granulosus genotypes or strains were identified through use of Bioinformatics tools: BioEdit, BLAST and MEGA6. The major finding of this study was the existence of a limited number of E. granulosus genotypes from cattle, goats, sheep and camels. The most predominant genotype was G1 (96.05\%), corresponding to the common sheep strain. To a limited extent (3.95\%), the study revealed the existence of Echinococcus canadensis $\mathrm{G} 6 / 7$ in three $(n=3)$ of the E. granulosus-positive samples. No other strains of E. granulosus were identified. It was concluded that the common sheep strain of Echinococcus sensu stricto and G6/7 of E. canadensis were responsible for echinococcal disease in Moroto district, Uganda.

\section{Introduction}

Echinococcosis in humans is one of the neglected zoonotic diseases. It is caused by metacestodes of the genus Echinococcus, with the main definitive host as the dog (Eckert et al. 2001). This genus includes small tapeworms of carnivores with larval stages known as hydatid cysts or metacestodes that proliferate in various organs of the intermediate hosts, including humans. The genus Echinococcus included four morphologically indistinct species (Echinococcus granulosus, Echinococcus multilocularis, Echinococcus oligarthrus and Echinococcus vogeli) until recently, when Echinococcus shiquicus and Echinococcus felidis were added as the fifth and sixth species (Huttner et al. 2008; Xiao et al. 2005).

Currently, there are four forms of hydatidosis that have been deemed taxonomically valid (Soulsby 1982). These include cystic echinococcosis (CE) (E. granulosus), alveolar echinococcosis (E. multilocularis) and polycystic echinococcosis (E. vogeli and E. oligarthrus). Of these, the most common form is cystic, followed by alveolar, echinococcosis. Alveolar echinococcosis is more severe and fatal than CE but sporadic and more difficult to treat because of its characteristic multiple budding and infiltration into organs, including the brain (Eckert et al. 2001).

CE is prevalent in sub-Saharan Africa (Macpherson \& Wachira 1997) and is caused by the metacestode of the dog tapeworm E. granulosus. The disease is currently considered an emerging zoonotic disease worldwide (Eckert et al. 2001), with an estimated global burden of over 1 million disability-adjusted life-years lost (Budke, Deplazes \& Torgerson 2006). This is almost equal to the burden caused by African trypanosomiasis and schistosomiasis (Budke, Deplazes \& Torgerson 2006). In China, for example, CE has been worse, with between 60000 and 1300000 people affected, with children accounting for one-third (Craig 2005).

$\mathrm{CE}$ transmission is more intense in remote pastoral communities or regions where veterinary services are poor and where dogs have easy access to animal carcasses and offal. It has been suggested that some of the risk factors responsible for human CE include livestock raising, pastoral

Copyright: @ 2016. The Authors. Licensee: AOSIS. This work is licensed under the Creative Commons Attribution License. 
life, gender, ethnicity, dog ownership, poor hygiene and low socio-economic status (Dowling, Abo-Shehada \& Torgerson 2000; Larrieu et al. 2002).

Economically, CE poses a threat to animal farming (Thompson 2008), leading to losses because of condemnation of edible organs, reduced meat and milk production, decreased hide and fleece value and decrease in fecundity (Polydorou 1981; Romazanov 1983). The public health concern is more critical, and as yet, there are no control measures in place. In eastern Africa, areas with high prevalence of human CE are said to be focally distributed in Kenya, northern Tanzania and South Sudan, with prevalence of at least $6 \%$ amongst nomadic populations (Macpherson et al. 1989). There is a significant public health problem amongst pastoralists in the region, especially the Turkana and Maasai communities in Kenya (French \& Nelson 1982). One of the highest reported incidences of human CE (220/100 000) in the world was in the Turkana district of north-western Kenya (French \& Nelson 1982). Likewise, in South Sudan, human CE is frequent in the extreme south-east of the country at the border with Kenya, where prevalence stands at 2\% $-3.5 \%$ as examined by ultrasound scans (Magambo et al. 1996; Magambo, Zeyhle \& Wachira 1998). In Uganda, Inangolet et al. (2010) conducted a study to establish the prevalence of E. granulosus amongst dogs in Karamoja and found the prevalence to be $66.3 \%$; however, no information on genotypes was provided. This information provides the background to the study.

\section{Materials and methods}

\section{Study area}

The study was conducted between February 2013 and August 2014 in Moroto district, sub-region of Karamoja. Karamoja sub-region is located in north-eastern Uganda and comprises seven districts, namely Abim, Amudat, Kaabong, Kotido, Moroto, Nakapiripirit and Napak. The coordinates of the town (Moroto) are $2^{\circ} 31^{\prime} 48.0^{\prime \prime} \mathrm{N}, 34^{\circ} 40^{\prime} 12.0^{\prime \prime} \mathrm{E}$ (Latitude: 2.5300; Longitude: 34.6700$)$. It is bordered in the North by South Sudan, in East by Turkana region and in the West by Pokot district of Kenya. Moroto district was chosen because of high incidences of CE (Inangolet et al. 2010) and its proximity to Turkana (Figure 1), which once had the world's highest incidences (Macpherson 1998; Macpherson et al. 1989).

\section{Study design}

This was a descriptive study where samples were obtained from livestock at Moroto Municipal Council abattoir. Details of the species of slaughter livestock (Table 1) were recorded including numbers of livestock. Upon inspection, infected organs were isolated and stored until a large sample size ( $n \geq 20$ samples) was reached. Samples were collected every 3 months and transported to Makerere University Molecular Biology Laboratory for testing.

\section{DNA extraction}

DNA extraction from tissue samples was performed as described by Nakao, Sako and Ito (2003), where small sections of the hydatid cysts or single isolated protoscolices were lysed using $20 \mu \mathrm{L}$ of $0.02 \mathrm{M} \mathrm{NaOH}$, heated at $99^{\circ} \mathrm{C}$ for 10 minutes and used directly as template.

\section{Nested polymerase chain reaction amplification}

First amplification of the NADH dehydrogenase 1 gene (NADH 1 gene) was performed as described by Addy et al. (2012) using primers nad A (5'TGT TTT TGA GAT CAG TTC GGT GTG 3') and nad C (5'CAT AAT CAA ACG GAG TAC GAT TAG 3') as forward and reverse primers, respectively. A $25-\mu \mathrm{L}$ reaction mixture containing $2.5 \mu \mathrm{L}$ of polymerase chain reaction (PCR) buffer ( $\mathrm{pH} 8.3$ ), $2.0 \mu \mathrm{L}$ of $2 \mathrm{mM} \mathrm{MgCl}_{2}, 0.5 \mu \mathrm{L}$ of $200 \mu \mathrm{M}$ of each dNTP, $0.625 \mu \mathrm{L}$ of $12.5 \mathrm{pmol}$ of each primer, $0.125 \mu \mathrm{L}$ of $1.25 \mathrm{U}$ of Taq polymerase and $2.0 \mu \mathrm{L}$ of template DNA were subjected to PCR conditions of denaturation at $94{ }^{\circ} \mathrm{C}$ for 5 minutes and then $94^{\circ} \mathrm{C}$ for 30 seconds. Annealing was carried out at $55^{\circ} \mathrm{C}$ for 30 seconds, elongation at $72{ }^{\circ} \mathrm{C}$ for 1 minute, then final elongation at $72{ }^{\circ} \mathrm{C}$ for 5 minutes for 35 cycles. The target product size was 1075 base pairs (bp).

A second amplification was carried out under the same conditions using $2.0 \mu \mathrm{L}$ of amplicon (produced with first amplification) with primers nad B (5'CAG TTC GGT GTG CTT TTG GGT CTG $\left.3^{\prime}\right)$ and nad D (5'GAG TAC GAT TAG TCT CAC ACA GCA 3') as forward and reverse primers, respectively. The product size for this amplification was 850 bp (Addy et al. 2012).

\section{Restriction fragment length polymorphism}

Fifteen microlitres of the nested PCR amplicons was digested using $0.5 \mu \mathrm{L}$ of $\mathrm{Hph}$ I restriction [recognition sequences; $5^{\prime} \ldots$ GGTGA $\left(\mathrm{N}_{8}\right)^{*} \ldots 3^{\prime}$ and $3^{\prime} \ldots$..CCACT $\left.\left(\mathrm{N}_{7}\right) * \ldots 5^{\prime}\right]$ enzyme in presence of $7.5 \mu \mathrm{L}$ of nuclease-free water and $2.0 \mu \mathrm{L}$ of $10 \mathrm{X}$ buffer B as instructed by the manufacturer (Fermentas, $\mathrm{GMBH}$, Germany). Restriction was performed overnight at $37{ }^{\circ} \mathrm{C}$. The $\mathrm{Hph} \mathrm{I}$ restriction endonuclease produced a staggered cut at nucleotide positions AT or TA bp 8 bp or 9 bp away from the recognition sequences. Echinococcus granulosus sensu stricto (G1-G3) restriction was expected to produce approximately 425 bp, 320 bp and 204 bp, whilst Echinococcus canadensis (G6/7) was expected to produce approximately $425 \mathrm{bp}$ and $107 \mathrm{bp}$ following online restriction mapping.

\section{Agarose gel electrophoresis}

Successful amplification of E. granulosus NADH 1 gene was determined by electrophoresis on $1.5 \%$ agarose gel prepared in $1 X$ tris acetate ethylenediaminetetraacetic acid (TAE) buffer containing $1 \%$ ethidium bromide, whilst successful digestion of the NADH 1 gene was electrophoresed on $2.0 \%$ agarose prepared in 1X TAE buffer with $1 \%$ ethidium bromide. Electrophoresis was performed at $120 \mathrm{~V}$ for $45-55$ minutes; separated fragments were visualised under UV transillumination. 


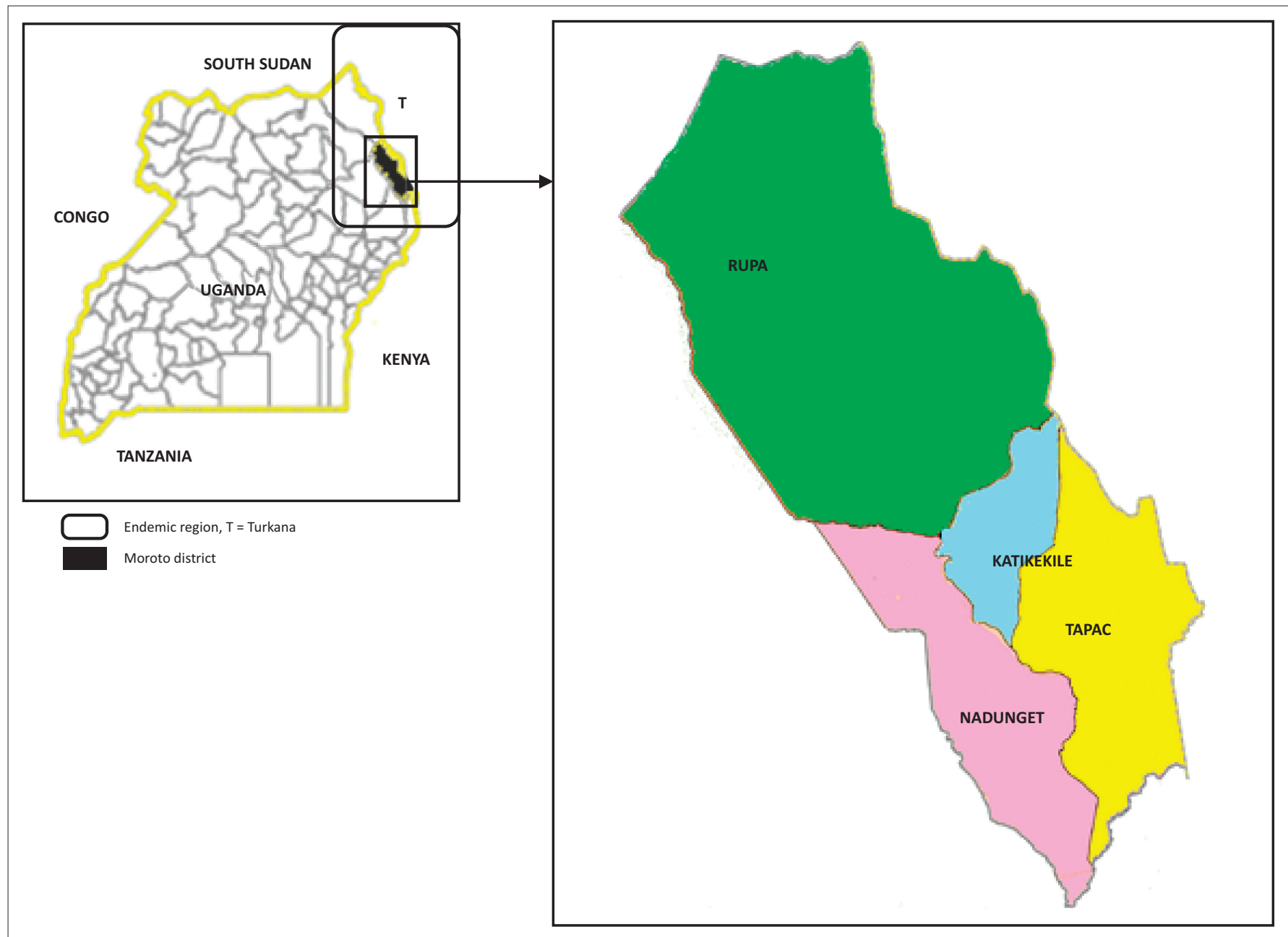

Source: Uganda Communications Commission, 2010, 'Uganda Communications Commission (UCC) Support through the Rural Communication Development Fund Programme', in UCC (Ed.), RCDF Projects in Moroto District, Uganda, p. 1, Uganda Communications Commission, Bugologi, Kampala

FIGURE 1: Map of Uganda showing one of echinococcal endemic regions (circled pattern) and administrative sub-counties of Moroto district.

TABLE 1: Areas of origin and number of animals that were considered for genotyping of Echinoccocus granulosus strains.

\begin{tabular}{|c|c|c|c|c|c|}
\hline \multirow[t]{2}{*}{ Origin } & \multicolumn{4}{|c|}{ Number of animals } & \multirow[t]{2}{*}{ Total } \\
\hline & Cattle & Goats & Sheep & Camels & \\
\hline Nadunget & 32 & 5 & 4 & 0 & 41 \\
\hline Rupa & 30 & 3 & 2 & 0 & 35 \\
\hline Katikekile & 15 & 2 & 1 & 0 & 18 \\
\hline Tapac & 8 & 1 & 0 & 1 & 10 \\
\hline Total & 85 & 11 & 7 & 1 & 104 \\
\hline
\end{tabular}

\section{Sequencing}

Ten percent $(n=8)$ of the samples that produced the G1-G3 banding patterns on restriction fragment length polymorphism (RFLP) and all the samples $(n=3)$ that produced G6/7 patterns were sent for Sanger DNA sequencing assay at Inqaba Biotech Industries Ltd, South Africa.

\section{Data analysis}

Gels were photographed and bands manually analysed against positive and negative controls. Following DNA sequencing, chromatograms were visually analysed using BioEdit Sequence Alignment Editor Software. Genotypes were determined online using the National Centre for Biotechnology Information (NCBI) Blast computer programme for homology (http:/ /www.ncbi.nlm.nih.gov/ blast/Blast.cgi) against published sequences in the GenBank. Pairwise sequence alignments were made using the online BLAST programme against reference sequences obtained from the GenBank. Genetic relatedness of the E. granulosus genotypes were determined using MEGA6 software. The Muscle programme of this software was used for multiple sequence alignments, trimming was carried out and phylogenetic analysis was accomplished using the phylogeny programme of the same software.

\section{Results}

A total of 2624 samples from ruminant livestock, including cattle, goats, sheep and camels slaughtered at Moroto Municipal Council abattoir, were examined by a Veterinary Officer for the presence of hydatid cysts in visceral organs. Of the examined animals, 104 that had suspected cysts were sampled (Table 1). These samples were subject to PCRRFLP for genotyping E. granulosus strains (Addy et al. 2012) and $10 \%$ of positive samples for DNA sequencing. A majority, $81.2 \%(n=85)$ of the suspected samples, were 
collected from cattle, $10.6 \%(n=11)$ were from goats, $6.7 \%$ $(n=7)$ were from sheep, whilst only $0.96 \%(n=1)$ was extracted from a camel (Table 1).

\section{Amplification of Echinococcus granulosus NADH 1 gene}

Of the suspected 104 samples, successful amplification of the E. granulosus NADH 1 gene occurred in $73.1 \%(n=76)$ of the samples producing a band of approximately $850 \mathrm{bp}$, whilst $26.9 \%(n=28)$ were not successfully amplified. Figure 2 shows a representative gel for the E. granulosus NADH 1 gene PCR products on 1.5\% 1X TAE agarose gel electrophoresis.

\section{Genotyping of Echinococcus granulosus strains in Moroto district by restriction fragment length polymorphism}

Of the E. granulosus NADH 1 gene successfully amplified samples $(n=76), 96.05 \%(n=73)$ were genotyped by RFLP as G1-G3, whilst, 3.95\% $(n=3)$ were G6/7. A representative gel following restriction of nested PCR product by Hph I was as shown in Figure 3.

\section{Genotyping of Echinococcus granulosus strains in Moroto district by sequencing}

Following the inability of RFLP genotyping assay to resolve genotypes G1-G3 and G6/7, 10\% of the samples that yielded the G1-G3 $(n=8)$ restriction pattern and all three that produced the G6/7 patterns were subjected to DNA sequencing. Using a BLAST search, sequences were compared with published sequences in the NCBI GenBank (Table 2).

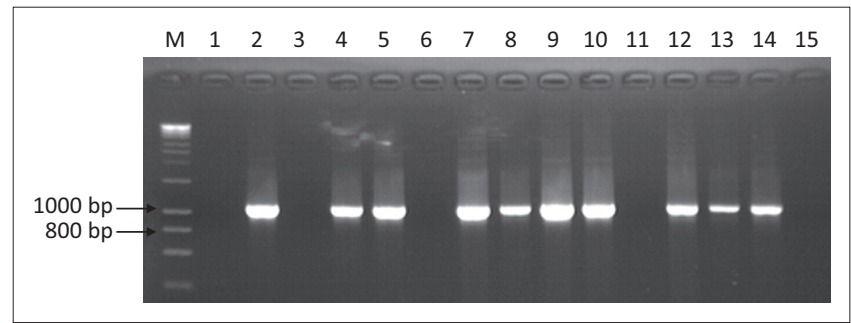

Lane M: molecular marker; Lanes 1-12 are test samples; Lanes 13-14 are G6/7-positive controls; Lane 15: negative control.

FIGURE 2: A 1.5\% agarose gel showing Echinococcus granulosus NADH 1 gene nested PCR analysis results.
All the samples $(n=8)$ that yielded the G1-G3 pattern were homologous to the common sheep G1 strain with maximum identity of $99 \%$. Meanwhile, $66.7 \%(n=2)$ of the samples that produced the $\mathrm{G} 6 / 7$ restriction pattern remained unresolved because they showed homology with both G6 and G7 GenBank reference sequences at 99/100\% maximum sequence identity. One $(n=1)$ of the sequences that yielded G6/7 RFLP pattern was homologous at 99\% maximum sequence identity to the G6 strain alone, although with a poor E-score $\left(4 \mathrm{e}^{-155}\right)$.

\section{Phylogenetic analysis}

Of the 11 samples that were subjected to DNA sequencing, 10 produced uniformly sized sequences $(\approx 520 \mathrm{bp}$ ). Only one (MRT049) produced a shorter sequence ( $\approx 312 \mathrm{bp}$ ); it was not used in MEGA alignment and phylogenetic analysis. Therefore, 10 sequences were considered for comparison with other sequences in the NCBI GenBank. The criterion for the NCBI sequence selection absolutely relied on the genotype and size of the sequences (> $700 \mathrm{bp}$ ). Of these, eight sequences belonged to G1 genotype whilst two sequences belonged to G6/ 7 genotype. Table 3 shows sequences selected from NCBI GenBank for phylogenetic analysis.

Genetic relatedness of test isolates with those in GenBank was assessed using Maximum Likelihood method based on the Hasegawa-Kishino-Yano model (Hasegawa, Kishino \& Yano 1985) and revealed two large clades. Clade A comprised G1s in which the G1 isolates from the present study clustered with those of Morocco, China, Argentina and India. Clade B cluster comprised the G6/7 isolates from the

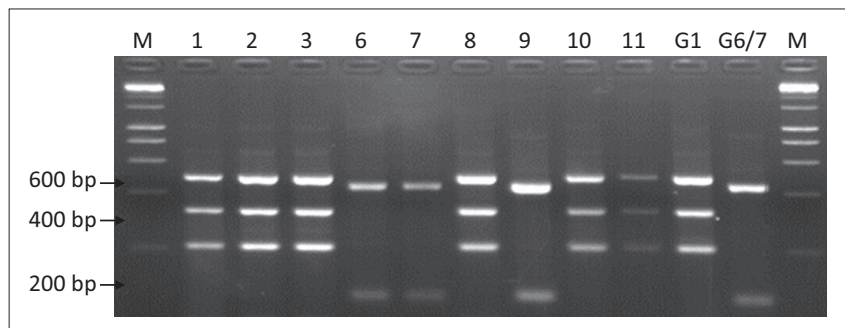

Lanes M: molecular marker; Lanes 1-11 are test samples; Lane G1: E. granulosus sensu stricto positive control (G1-G3); Lane G6/7: Echinococcus canadensis-positive control.

FIGURE 3: A 2.0\% agarose gel showing Echinococcus granulosus NADH 1 gene RFLP analysis results.

TABLE 2: Comparison of test sequences with those from the GenBank.

\begin{tabular}{|c|c|c|c|c|c|c|c|}
\hline Number & Sample & RFLP & Sequencing results & Maximum identity (\%) & E-value & GenBank accessions & Other accessions \\
\hline 1 & MRT3A & G1-G3 & G1 & 99 & 0 & KJ556993 & EF367321 \\
\hline 2 & MRT08 & G1-G3 & G1 & 99 & 0 & KJ556993 & EF367321 \\
\hline 3 & MRT60A & G1-G3 & G1 & 99 & 0 & KJ556993 & EF367321 \\
\hline 4 & MRT61 & G1-G3 & G1 & 99 & 0 & KJ556993 & EF367321 \\
\hline 5 & MRT66 & G1-G3 & G1 & 99 & 0 & KJ556993 & EF367321 \\
\hline 6 & MRT76 & G1-G3 & G1 & 99 & 0 & KJ556993 & EF367321 \\
\hline 7 & MRT77 & G1-G3 & G1 & 99 & 0 & KJ556993 & EF367321 \\
\hline 8 & MRT78 & G1-G3 & G1 & 99 & 0 & KJ556993 & EF367321 \\
\hline 9 & MRT47 & $\mathrm{G} 6 / 7$ & G6/7 & $100 / 99$ & 0 & AB208063 & AB235847 \\
\hline 10 & MRT48 & G6/7 & G6/7 & $100 / 99$ & 0 & AB208063 & AB235847 \\
\hline 11 & MRT49 & G6 & $\mathrm{G} 6 / 7$ & 99 & $5 e^{-155}$ & HM749618 & HM749617 \\
\hline
\end{tabular}

RFLP, restriction fragment length polymorphism. 
TABLE 3: Test sequences (MRT) and GenBank accession numbers for sequences used in phylogenetic tree construction.

\begin{tabular}{|c|c|c|c|c|c|}
\hline Accession number & Genotype & Host species & Year of identification & Country of origin & Maximum identity (\%) \\
\hline Chamai et al. (MRT03A) & G1 & Cattle & 2014 & Uganda & - \\
\hline Chamai et al. (MRT08) & G1 & Cattle & 2014 & Uganda & - \\
\hline Chamai et al. (MRT060A) & G1 & Cattle & 2014 & Uganda & - \\
\hline Chamai et al. (MRT061) & G1 & Cattle & 2014 & Uganda & - \\
\hline Chamai et al. (MRT066) & G1 & Cattle & 2014 & Uganda & - \\
\hline Chamai et al. (MRT076) & G1 & Cattle & 2014 & Uganda & - \\
\hline Chamai et al. (MRT077) & G1 & Cattle & 2014 & Uganda & - \\
\hline Chamai et al. (MRT078) & G1 & Cattle & 2014 & Uganda & - \\
\hline Chamai et al. (MRT047) & $\mathrm{G} 6 / 7$ & Cattle & 2014 & Uganda & - \\
\hline Chamai et al. (MRT048) & G6/7 & Cattle & 2014 & Uganda & - \\
\hline EF367332 & G1 & Sheep & 2007 & Morocco & 99 \\
\hline EF367319 & G1 & Sheep & 2007 & Morocco & 100 \\
\hline KJ556993 & G1 & Human & 2014 & China & 100 \\
\hline KC579442 & G1 & Cattle & 2013 & Argentina & 99 \\
\hline EF090610 & G1 & Sheep & 2006 & India & 99 \\
\hline AB208063 & G6 & Camel & 2009 & Kazakhstan & 100 \\
\hline AB235847 & G7 & Pig & 2009 & Japan & 99 \\
\hline KJ556995 & G7 & Human & 2014 & China & 99 \\
\hline AB235848 & G8 & Moose & 2009 & Japan & 97 \\
\hline KJ663949 & G10 & Human & 2014 & China & 98 \\
\hline
\end{tabular}

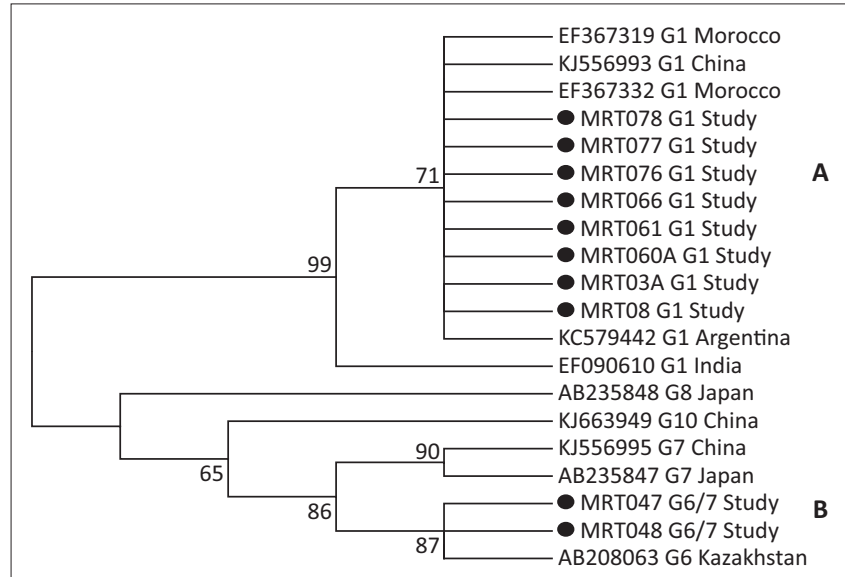

Key: - Test sequences; A and B: clades; NB: MRT049 was not included because of its short size as compared with other sequences

Note: The evolutionary history was inferred using the Maximum Likelihood method based on the Hasegawa-Kishino-Yano model (Hasegawa, Kishino \& Yano 1985). The tree with the highest log likelihood (-865.3136) is shown. The percentage of trees in which the associated taxa clustered together is shown next to the branches. Initial tree(s) for the heuristic search were obtained by applying the Neighbour-Joining method to a matrix of pairwise distance estimated using the Maximum Composite Likelihood approach. The analysis involved 20 nucleotide sequences. All positions containing gaps and missing data were eliminated. There were a total of 427 positions in the final data set. Evolutionary analyses were conducted in MEGA6 (Tamura et al. 2013).

FIGURE 4: Molecular phylogenetic analysis of test isolates along with National Centre for Biotechnology Information published sequences by Maximum Likelihood method.

present study along with genotypes G6-10 from Japan, China and Kazakhstan (Figure 4). No published GenBank sequences were obtained from East Africa countries including Uganda.

\section{Discussion}

This is the first study to genetically characterise the genotypes of E. granulosus amongst livestock in Uganda. Our data clearly showed the predominance of E. granulosus genotype G1 $(96.05 \%)$ corresponding to the common sheep strain, with a minority (3.95\%) of cases being E. canadensis (G6/7) genotype. None of the other strains reported elsewhere, including the buffalo strain (G3), the equines strain (G4) and the still poorly characterised cervid strains (G8, G9 and G10) were found in this sample from Moroto district. Our findings were in agreement with those of Addy et al. (2012), who reported the predominance of genotype G1 (almost 100\%) in neighbouring Kenya, but they also reported the occurrence of E. ortleppi genotype, not found in our study.

Our findings differed from studies conducted in Sudan, which reported predominance of the camel strain (G6) and to a lesser extent $(<26 \%)$, the cattle strain (G5) (Dinkel et al. 2004; Omer et al. 2010). Some African camel-rearing countries like Algeria, Libya and Tunisia have also reported the existence and predominance of G1 over G6/7 (Abushhewa et al. 2010; Farjallah et al. 2007; Maillard et al. 2007). This could be attributed to continental globalisation of the common sheep strain (G1) from Europe (Spain and Portugal) to northern African countries, especially Libya, Algeria and Morocco, which are geographical neighbours. These reports indicate regional variations of the E. granulosus genotypes, although the common sheep strain (G1) appears to be predominant. In Turkey, for example, Snabel et al. (2009) also reported the sheep strain (G1) as the predominant genotype.

Our data suggest that the E. granulosus genotypes circulating in dogs and livestock in Karamoja region could be originating from the neighbouring Turkana region of Kenya. The borders between these regions are porous, with unrestricted movement of livestock; moreover, the lifestyle of the Karamojong and Turkana could also be a major factor that explains existence and persistence of echinococcosis in these areas. The lifestyle of these pastoralists is mainly characterised by close interaction with dogs, poor hygiene, insufficient veterinary services and lack of knowledge of disease and its mode(s) of transmission. Besides these, unending cattle rustling practices amongst these nomadic groups could also explain the spread of echinococcosis between Karamoja sub-region and Turkana of Kenya. 
In agreement with Eryildiz and Sakru (2012), both genotypes (test genotypes) were closely related to other studies. Most of the clade A study Moroto (MRT) G1 strains shared the same node with other strains, indicating a monophyletic relationship. This meant that the G1 genotypes of other studies were homologous with G1s of the study. Similarly, clade B strains, which included the study MRT G6/7, also revealed origin from a common ancestry. Although the study revealed a divergence at the basal nodes with reduced bootstrap values in clade $B$, this could be explained by earlier claims of poor characterisation in the E. canadensis (G6-G10) group, as reported by Boubaker et al. (2013). Nevertheless, genotypes G8 and G10 in particular showed greater distinctness from the others, which almost rendered the relationship in clade $B$ paraphyletic. This distinctness could be attributed to the fact that both are cervid strains (wild) as compared with the rest of the strains that are domestic. This did not, however, rule out common ancestry with the rest of clade B genotypes.

The biggest setback to the study was the absence of published eastern Africa GenBank sequences, especially for Kenya and Uganda, because it was believed that Moroto echinococcal disease was shared with Turkana of Kenya, but it was not possible to compare the study findings with other eastern African countries. This therefore presented a missed opportunity for a better understanding of E. granulosus genotype distribution in eastern Africa, especially in Uganda (Moroto), Kenya (Turkana) and South Sudan (Toposa). The study was also hindered by the low resolution power of the RFLP assay that failed to distinguish between G1-G3 and G6/7 genotypes, although this was circumvented through DNA sequencing, which was costly.

\section{Conclusion}

The project determined the strains of the dog tapeworm responsible for the echinococcal disease amongst livestock in Moroto district (Karamoja area) to be the common sheep strain (G1) of Echinococcus sensu stricto and E. canadensis (G6/7). No other strains of E. granulosus were identified.

Our finding of predominance of the G1 genotype in Moroto district (Karamoja), a genotype identified as the chief causative agent of hydatidosis across all species, calls for institution of strict public health measures that include meat inspection, proper disposal of cystic organs to avoid access by dogs and restriction of movement of animals from one area to another. Notably, the study needs to be complemented with studies amongst humans and dogs. This will help to map a linkage between the definitive host, the grazing intermediate ungulates and humans who are adversely affected by this infection compared with other intermediate hosts. This will make understanding of the disease epidemiology better in Karamoja, hence better public health mitigation and treatment strategies.

\section{Acknowledgements}

We thank Cystic Echinococcosis in sub-Saharan Africa Research Initiative for financially supporting the study and Prof. Michael Ocaido and Prof. Joseph Erume for supervision and guidance. We also thank Silver Ochwo and our entire M.Sc. Molecular Biology fraternity (2011) for their advice and guidance. Special thanks go to Erastus Mulinge and Dr. Cecilia Mbae of Kenya for guidance in Molecular work.

\section{Competing interests}

The authors declare that they have no financial or personal relationships which may have inappropriately influenced them in writing this article.

\section{Authors' contributions}

M.C. developed the proposal, collected samples, performed laboratory analyses, interpreted data and wrote the thesis. L.O. supported proposal development, collected samples and supported thesis writing. J.E. supervised proposal development, performed laboratory analyses and supported thesis writing. M.O. supervised proposal development, performed laboratory analysis and supported thesis writing. P.O. collected samples and performed laboratory analysis. E.O. supported proposal development. S.B. supported laboratory analyses and supported in result interpretation. A.K. performed the laboratory analyses.

\section{References}

Abushhewa, M.H., Abushhiwa, M.H., Nolan, M.J., Jex, A.R., Campbell, B.E., Jabbar, A. et al., 2010, 'Genetic classification of Echinococcus granulosus cysts from humans, cattle and camels in Libya using mutation scanning-based analysis of mitochondrial loci', Molecular and Cellular Probes 24, 346-351.

Addy, F., Alakonya, A., Wamae, N., Magambo, J., Mbae, C., Mulinge, E. et al., 2012 'Prevalence and diversity of cystic echinococcosis in livestock in Maasailand, Kenya', Parasitology Research 111(6), 2289-2294.

Boubaker, G., Macchiaroli, N., Prada, L., Cucher, M.A., Rosenzvit, M.C., Ziadinov I. et al., 2013, 'A multiplex PCR for the simultaneous detection and genotyping of the Echinococcus granulosus complex', PLoS Neglected Tropical Diseases 7 , e2017.

Budke, C.M., Deplazes, P. \& Torgerson, P.R., 2006, 'Global socioeconomic impact of cystic echinococcosis', Emerging Infectious Diseases 12, 296-303.

Craig, P.S., 2005, 'Epidemiology of human alveolar echinococcosis in China', Parasitology International 55, 221-225.

Dinkel, A., Njoroge, E.M., Zimmermann, A., Walz, M., Zeyhle, E., Elmahdi, I.E. et al., 2004, 'A PCR system for detection of species and genotypes of the Echinococcus granulosus-complex, with reference to the epidemiological situation in eastern Africa', International Journal for Parasitology 34, 645-653.

Dowling, P.M., Abo-Shehada, M.N. \& Torgerson, P.R., 2000, 'Risk factors associated with human cystic echinococcosis in Jordan: Results of a case-control study', Annals of Tropical Medicine and Parasitology 94, 69-75.

Eckert, J., Schantz, P.M., Gasser, R.B., Torgerson, P.R., Bessonov, A.S. \& Movsessian, S.O., 2001, 'Geographical distribution and prevalence', in J. Eckert, M.A. Gemmell, F.X Meslin \& Z.S. Pawłowski (eds.), WHO/OIE manual on echinococcosis in humans and animals: A public health problem of global concern, pp. 100-142, World Health Organization, Paris.

Eryildiz., C. \& Sakru, N., 2012, 'Molecular characterization of human and animal isolates of Echinococcus granulosus in the Thrace Region, Turkey', Balkan Medical Journal 29(3), 261-267.

Farjallah, S., Busi, M., Mahjoub, M.O., Slimane, B.B., Said, K. \& D’amelio, S., 2007, 'Molecular characterization of Echinococcus granulosus in Tunisia and Mauritania by mitochondrial rrnS gene sequencing', Parassitologia 49, 239-246.

French, C.M. \& Nelson, G.S., 1982, 'Hydatid disease in the Turkana District of Kenya II. A study in medical geography', Annals of Tropical Medicine and Parasitology 76, 439-457.

Hasegawa, M., Kishino, H. \& Yano, T., 1985, 'Dating the human-ape split by a molecular clock of mitochondrial DNA', Journal of Molecular Evolution 22, 160-174. 
Huttner, M., Nakao, M., Wassermann, T., Siefert, L., Boomker, J.D.F., Dinkel, A., Sako, Y. et al., 2008, 'Genetic characterization and phylogenetic position of Echinococcus
felidis Ortlepp, 1937 (Cestoda: Taeniidae) from the African lion', International Journal for Parasitology 38, 861-868.

Inangolet, F.O., Biffa, D., Opuda-Asibo, J., Oloya, J. \& Skjerve, E., 2010, 'Distribution and intensity of Echinococcus granulosus infections in dogs in Moroto district, Uganda', Tropical Animal Health and Production 42, 1451-1457.

Larrieu, E.J., Costa, M.T., Del Carpio, M., Moguillansky, S., Bianchi, G. \& Yadon, Z.E., 2002, 'A case-control study of the risk factors for cystic echinococcosis among the children of Rio Negro province, Argentina', Annals of Tropical Medicine and Parasitology 96, 43-52.

Macpherson, C.N.L., 1998, 'Improving the health of nomadic people - The example of cystic hydatid disease', World Health 51(4), 18-19.

Macpherson, C.N., Spoerry, A., Zeyhle, E., Romig, T. \& Gorfe, M., 1989, 'Pastoralists and hydatid disease: An ultrasound scanning prevalence survey in East Africa' Transactions of the Royal Society for Tropical Medicine and Hygiene 83, 243-247.

Macpherson, C.N.L. \& Wachira, T.M., 1997, 'Cystic echinococcosis in Africa south of the Sahara', in F.L. Andersen, H. Ouhelli \& M. Kachani (eds.), Compendium of cystic echinococcosis in Africa and in middle Eastern Countries with special reference to Morocco, pp. 245-277, Brigham Young University, Provo.

Magambo, J.K., Hall, C., Zeyle, E. \& Wachira, T.M., 1996, 'Prevalence of human hydatid disease in southern Sudan', African Journal of Health Sciences 3, 154-156.

Magambo, J.K., Zeyhle, E. \& Wachira, T., 1998, 'Hydatid disease in Toposaland Southern Sudan', African Journal of Health Sciences 5, 129-132.

Maillard, S., Benchikh-Elfegoun, M.C., Knapp, J., Bart, J.M.,, Koskei, P., Gottstein, B. et al., 2007, 'Taxonomic position and geographical distribution of the common sheep G1, and camel G6 strains of Echinococcus

Nakao, M., Sako, Y. \& Ito, A., 2003, 'Isolation of polymorphic microsatellite loci from the tapeworm Echinococcus multilocularis', Infection, Genetics and Evolution 3, 159-163.
Omer, R.A., Dinkel, A., Romig, T., Mackenstedt, U., Elnahas, A.A., Aradaib, I.E. et al., 2010, 'A molecular survey of cystic echinococcosis in Sudan', Veterinary Parasitology 169, 340-346.

Polydorou, K., 1981, 'Animal health and economics. Case study: Echinococcosis with reference to Cyprus', Bulletin de l'Office International des Épizooties 93(5/6), 981-992.

Romazanov, V.T., 1983, 'Evaluation of economic losses due to echinococcosis', in A. Lysendo (ed.), Zoonosis control: Collection of teaching aids for international training course, vol. II, pp. 283-285, Centre of International Projects GKNT, Moscow.

Snabel, V., Altintas, N., D’amelio, S., Nakao, M., Romig, T., Yolasigmaz, A. et al., 2009 'Cystic echinococcosis in Turkey: Genetic variability and first record of the pig strain (G7) in the country', Parasitology Research 105, 145-154.

Soulsby, E.J., 1982, Helminths, arthropods and protozoa of domesticated animals, 7th edn., Baillière Tindall, London.

Tamura, K., Stecher, G., Peterson, D., Filipski, A. \& Kumar, S., 2013, 'MEGA6: Molecular evolutionary genetics analysis version 6.0', Molecular Biology and Evolution 30(12), 2725-2729.

Thompson, R.C., 2008, 'The taxonomy, phylogeny and transmission of Echinococcus', Experimental Parasitology 119, 439-446.

Uganda Communications Commission, 2010, 'Uganda Communications Commission (UCC) Support through the Rural Communication Development Fund Programme', in UCC (Ed.), RCDF Projects in Moroto District, Uganda, p. 1, Uganda Communications Commission, Bugologi, Kampala.

Xiao, N., Qiu, J., Nakao, M., Li, T., Yang, W., Chen, X., Scantz P.M. et al., 2005, 'Echinococcus shiquicus $\mathrm{n}$. sp., a taeniid cestode from Tibetan fox and plateau pika in China', International Journal for Parasitology 35(6), 693-701. 